\title{
Wild Heritage of South Africa, by Douglas Hey. O.U.P.,
}

R.7.05: U.K. 84s.

This is yet another cogent plea for effective wildlife conservation before it is too late, and it would have been preferable to focus attention on this by starting, not ending, with the chapter on "The Conservation of Wild Life," followed by the graphic exposition on "Man and Wild Life."

"Formerly man was controlled largely by his environment and the forces of nature, today he is beginning to control his environment," says the author. How right he is. The senseless dissipation of a priceless asset is man's handiwork, and indeed it is a sad commentary that now conservation of wild animals is advocated primarily for tourism i.e. pecuniary profit, and for their utility, instead of for themselves.

Profusely illustrated, with many drawings of outstanding merit, it is a pity that the high standard of some has not been maintained throughout, really shocking is that of the puff adder on p. 121. These illustrations depict a range of wild life, including flora, from micro-organisms to elephants and whales, but nowhere is there an indication of relative size. This detracts seriously from their value.

Nevertheless, this is a comprehensive and richly informative tome. The talented Director of Nature Conservation in the Province of the Cape of Good Hope, who is dedicated to his vocation, has gone to infinite pains to provide a wealth of knowledge which is almost bewildering in its scope. One hopes it will achieve the wide distribution it deserves.

C. R. S. PITMAN

A Continent in Danger, by Vincent Serventy. Deutsch, 45s. The Great Extermination, edited by A. J. Marshall. Heinemann, 42s.

Captain Cook, exploring the coast of Australia only 197 years ago, found species of a primitive fauna, a beautiful and interesting flora, indigenous tribes living in the stone age, and a countryside magnificent and varied. Australia has been separated from the Asian land mass for so long that much of the fauna and flora have retained their original primitive characteristics, unique on earth today. Vincent Serventy's enthrallingly interesting and beautifully presented book, with spectacular illustrations in both colour and black and white, presents with great sensitivity an intimate picture of the mammals, birds, and reptiles of the continent and of the environment in which they live. Both he and Professor Marshall with his co-authors describe the devastating effect of the impact of Western civilisation on this unique fauna and flora.

Professor Marshall does not pull his punches in apportioning blame for the present deplorable state of affairs. The first settlers had to clear the land for agriculture; to them the forest was not a friend but an enemy, and they were very wasteful in their methods. Fire was the normal method of clearing the thick undergrowth; animals which ate the grass or which they believed preyed on their flocks and herds, had to be destroyed. Finally, to remind them of home, they introduced exotic birds, mammals and plants-a menace to the indigenous flora and fauna. Today the destruction of the habitat by fire, axe and saw and machines, and the introduction of exotics, together with shooting, trapping and poisoning continues and threatens the survival of many species. How difficult it is to eradicate habits and methods passed on from father to son! Leonard 
Webb's chapter "The Rape of the Forests" gives a graphic picture of the devastation caused by ignorance and faulty land use in the wonderful indigenous forests of eastern Australia, and an enthralling chapter on "The Decline of the Plants" by J. S. Turner gives an excellent exposition of a great heritage and the dangers that assail it. Ian D. Hiscock, writing on "The Shores and the Shallows," not only gives a clear picture of the amazing marine life of the Great Barrier Reef and the Australian coast, but of the destruction which is endangering much that is irreplaceable.

The authors of these two well written books face these problems squarely; they agree that a solution can only be reached by education, research, and legislation. Sanctuaries, in every type of terrain, and in every variation of climate must be declared, and policed. If immediate action is taken much can still be saved; delay will be disastrous. Australia covers a vast area. Naturalists are few, and it may well be that there will be many exciting and happy surprises in store. The famous ornithologist Alec Chisholm recently stated that in spite of the tremendous destruction that has taken place, there is no evidence at all to indicate that any one kind of bird on the continent (excluding the islands) has definitely become extinct since settlement began nearly two hundred years ago. In fact during recent years fifty new birds have been added to the country's roll call, fifteen of them since 1960 . Unfortunately the same cannot be said of the marsupials; ten forms have become extinct-all but one since 1900-and no fewer than 32 are currently regarded as in danger of extinction. Both books should be read by every Australian citizen, young and old, but they are also of great interest to nature lovers throughout the world.

HENRY ABEL SMITH

\section{The Primates, by Sarel Eimerl and Irven De Vore. Time-Life} International, 32s. 6d.

The Time-Life nature books form one of the best "popular wildlife series" so far published, each with an informative and easily readable text married to excellent photographs; the latest one about primates will not be a disappointment.

The book covers a great deal of ground, from defining what is a primate to the ways in which primatological studies are throwing some light on to our own evolution and behaviour. De Vore is well known for his field studies of baboons, and the results of his own work have been heavily drawn upon without appearing too obtrusive. However, it is perhaps a shame that some of the more recent investigations by V. and F. Reynolds, and Jane Goodall, on chimpanzees could not have figured more prominently in the book, and the virtual omission of the classic investigations by Carpenter on howler monkeys, together with the studies on the Japanese macaques, are perhaps puzzling. But any such criticism is by the way; no-one can fail to learn something from this book and many will no doubt finally close it with a greater appreciation of their own evolutionary and behavioural roots.

Conservation is not dealt with in any detail, although there are several photographs of caged orang-utans, of rhesus monkeys being used for medical research, and of the celebrated Ham, the first chimp in space. If apes or macaques look pitiful in the sterile surroundings of the research laboratory, how magnificent they are in their natural haunts, and the majority of the 153 photographs are a feast for the primate-lover's eyes.

JOHN SPARKS 